\title{
FAKTOR-FAKTOR YANG MEMPENGARUHI PERANAN PERANAN INSPEKTOR SEBAGAI INTERNAL AUDITOR DI KABUPATEN LUWU
}

\author{
SUMARNO, NURSAN, DR.SAPAR
}

\begin{abstract}
ABSTRAK
Dalam menjalankan peranan inspektorat sebagai internal auditor di pengaruhi oleh dua factor yakni factor internal dan factor eksternal. Tujuan penelitian adalah 1) Untuk mengetahui seberapa besar $p$ engaruh factor internal terhadap peranan inspektorat sebagai internal auditor di kabupaten luwu 2)Untuk mengetahui seberapa besar pengaruh factor eksternal terhadap peranan inspektorat sebagai internal auditor di kabupaten luwu. 3) untuk mengetahui seberapa besar pengaruh factor internal dan eksternal terhadap peranan inspektorat sebagai internal auditor di kabupaten luwu.

Data dalam penelitian ini merupakan data primer yang diperoleh dari penyebaran kuesioner secara langsung kepada seluruh auditor internal inspektorat kabupaten luwu sebanyak 15 orang. Analisis yang digunakan untuk menguji hipotesis adalah regresi linier berganda, dengan alat bantu SPSS.

Hasil penelitian ini menunjukkan factor internal dan factor eksternal secara simultan berpengaruh signifikan terhadap peranan internal auditor pada inspektorat kabupaten luwu sebesar 7,024 dengan signifikan 0,010, secara persial factor internal dari hasil perhitungan diperoleh angka t hitung sebesar 0,772 $<t$ table sebesar 2, 160 sehingga $H_{0}$ diterima dan $H_{1}$ ditolak. Artinya tidak ada hubungan linier antara factor internal. Besarnya pengaruh factor internal terhadap peranan internal auditor inspektorat, yaitu 0,152 atau 15\% dianggap tidak signifikan, sedangkan factor eksternal dari hasil perhitungan diperoleh angka thitung sebesar 3,538 $>t$ table sebesar 2,160 sehingga $H_{0}$ ditolak dan $H_{1}$ diterima. Artinya ada hubungan linier antara factor eksternal besarnya pengaruh factor eksternal terhadap peranan internal auditor inspektorat, yaitu 0,699 atau 70\% dianggap signifikan.

Kesimpulan dari hasil penelitian ini adalah secara persial factor internal tidak berpengaruh terhadap peranan inspektorat sebgai internal auditor, sedangkan factor eksternal berpengaruh dan secasra simultan kedua factor tersebut berpengaruh terhadap peranan inspektorat sebagai internal auditor. Diharapkan agar kita para auditor memperhatikan indicator factor internal dan eksternal dalam menjalankan peranannya serta diharapkan agar kiranya penelitian ini bisa dilanjutkan embai dengan berfokus pada variable yang belum diteliti.
\end{abstract}

Kata kunci: Inspektorat, Internal auditor, Eksternal auditor. 


\section{Pendahuluan}

\section{Latar Belakang}

Keuangan daerah merupakan komponen paling penting dalam perencanaanpembangunan, sehingga analisis mengenai kondisi dan proyeksi keuangan daerah perlu dilakukan untuk memperoleh kesadarn mengenai kemampuan daerah dalam menandai rencana pembangunan dan kesadaran untuk secara efektif memberikan perhatian kepada isu dan permasalahan strategis secara tepat.

Peran dan fungsi pengawasan di daerah merupakan salah satu hal yang harus di perhatikan oleh pemerintah daerah, karena dalam penyelenggaraan pemerintah daerah, terutama dalam pengelolaan keuangan daerah yang sering terjadi penyelewengan atau tindakan korupsi di dalamnya. Sehingga lembaga pengawasan dalam hal ini memiliki peranan penting dalam menciptakapengelolaan keuangan daerah yang akuntabel. Jadi dengan keakuntabilitasnya ini, semua kegiatan yang di lakukan dalam pengelolaan keuangan daerah dapat di pertanggungjawabkan hasilnya kepada pemerintah daerah itu sendiri dan pemerintah pusat.

Internal auditor dalam menjalankan tugas untuk mewujudkan akuntabilitas pengelolaan keuangan daerah harus mampu berperilaku yang baik sesuai dengan standar etika profesi auditor. Untuk itu, hal-hal yang dapat mengganggu kelancaran pada internal auditor dapat di cegah baik itu dari dalam diri maupun dari luar.

Berdasarkan uraian terasebut di atas, maka penulis tertarik untuk melakukan penelitian dengan menuangkan judul :" factor-faktor yang mempengaruhi peranan inspektorat sebagai internal auditor di kabupaten luwu ". Masalah penelitian ini adalah: (a) Seberapa besar pengaruh factor internal terhadap peranan inspektorat sebagai internal auditor di kabupaten luwu ?, (b) Seberapa besar pengaruh factor eksternal terhadap peranan inspektorat sebagai internal auditor di kabupaten luwu ?, (c) Seberapa besar pengaruh factor internal dan factor eksternal terhadap peranan sebagai internal auditor di kabupaten luwu ?. Tujuan penelitian ini adalah: (a) Untuk mengetahui seberapa besar pengaruh factor internal terhadap peranan inspektorat sebagai internal auditor di kabupaten luwu, (b) Untuk mengetahui seberapa besar pengaruh factor eksternal terhadap peranan inspektorat sebagai internal di kabupaten luwu

\section{Metode Penelitian}

Tempat dan Waktu Penelitian

Dalam melaksanakan kegiatan penelitian ini penulis memilih lokasi penelitian di inspektorat belopa kabupaten luwu. Peneliti melakukan penelitian di tempat tersebut karena inspektorat merupakan salah satu lembaga yang di harapkan mampu melakukan pengawasan, pemeriksaan dan pembinaan bagi instansi-instansi pemerintahan dalam hal akuntabilitas pengelolaan keuangan daerah. 
Jenis dan Sumber Data

1. Data primer merupakan data penelitian yang di peroleh langsung dari hasil kuesioner kepada para auditor internal yang ada di inspektorat Belopa kabupaten luwu.

2. Data sekunder merupakan data penelitian yang diperoleh secara tidak langsung melalui media perantara. Dalam penelitian ini data sekunder meliputi telaah literatur untuk membentuk tinjauan pustaka, penentuan atribut berdasarkan penelitian terdahulu atau dari teori yang ada untuk mengukur variable-variabel penelitian. Data sekunder diperoleh dari buku-buku, jurnal, internet, majalah, dan literature terkait lainnya.

Metode Pengumpulan Data

Metode pengumpulan data yang digunakan dalam penelitian ini adalah: Penelitian Lapangan ( field research ). Cara-cara yang di lakukan adalah : (a) Observasi, yaitu pengamatan dan pencatatan secara sistematis terhadap gejala/ fenomena yang diselidiki, (b) Interview, yaitu mengadakan wawancara langsung pada pihak-pihak yang dapat, (c) Kuesioner, yaitu daftar pertanyaan yang didistribusikan untuk diisi dandikembalikan atau dapat juga dijawab dibawah pengawasan peneliti ( Nasution, 2003 )

\section{Metode Analisis Data}

Metode analisis yang dipergunakan dalam penelitian ini adalah deskritif dengan menggunakan alat analisis statistic regresi linier berganda. Persamaaan regresi linier berganda mengandung makna bahwa dalam suatu persamaan regresi terdapat satu variable dependent dan lebih dari satu variable indevendent ( Algifari, 2000 ). Secara umum model regresi linier berganda dirumuskan sebagai berikut :

$\mathrm{Y}=\alpha+\beta_{1} \mathrm{X}_{1}+\beta_{2} \mathrm{X}_{2}+\mathrm{e}$

Keterangan :

$\mathrm{Y}=$ peranan internal auditor inspektorat

$\alpha=$ konstanta

$\mathrm{X}_{1}=$ factor internal

$\mathrm{X}_{2}=$ factor eksternal

$\beta_{1}=$ koefisien regresi factor internal

$\beta_{2}=$ koefisien regresi factor eksternal

$\mathrm{e}=$ eror

Uji Validitas dan Realibilitas

Validitas

Menurut sekaran ( 2003 ) validitas menunjukkan ketepatan dan kecermatan alat ukur dalam melakukan fungsi ukurnya. Suatu skala pengukuran disebut valid bila ia melakukan apa yang seharusnya di ukur. Bila skala pengukuran tidak valid maka ia tidak bermanfaat bagi peneliti karena ia tidsk mengukur apa yang seharusnya diukur atau melakukan apa yang seharusnya dilakukan. 


\section{Realiabilitas}

Uji realibilitas adalah berkaitan dengan masalah adanya kepercayaan terhadap instrumen. Suatu instrumen dapat memiliki tingkat kepercayaan yang tinggi ( konsisten ) jika hasil dari pengujian instrument tersebut menunjukkan hasil yang tetep.

Teknik statistic yang digunakan untuk pengujian tersebut dengan koefisien cronbach's alpha dengan bantuan software SPSS. Cronbach's alpha merupakan uji reabilitas untuk alternative jawaban lebih dari dua. Menurut supramono dan utami (2004 ) secara umum suatu instrumen dikatakan reliable jika memiliki koefesien cronbach's alpha $>0,6$.

Dengan sampel uji penelitian sebanyak 15 orang maka diperoleh hasil uji realibilitas disajikan dalam table berikut :

Table 1

Hasil uji reliabilitas data

\begin{tabular}{|l|l|l|l|}
\hline NO & Alpha & Cronbach Alpha & Realibilitas \\
\hline F11 - F19 & 0,866 & 0,6 & Reliabal \\
\hline FE1 - FE9 & 0,714 & 0,6 & Reliabel \\
\hline INI - IN9 & 0,913 & 0,6 & Reliabel \\
\hline
\end{tabular}

\section{Hasil Penelitian Dan Pembahasan}

Gambaran umum organisasi

Sejarah singkat

Inspektorat kabupaten luwu berdiri sejak tahun 2005 pada saat kabupaten luwu berpisah dengan kota palopo dan kemudian Belopa menjadi ibu kota kabupaten luwu. Sebelum otonomi daerah, insktorat bernama inspektorat wilayah kabupaten (ITWILKAB), setelah ekonomi daerah tepatnya tahun 2005 berubah nama menjadi badan pengawas daerah (BAWASDA) dan berdasarkan peraturan pemerintah nomor 41 tahun 2007 tentang struktur organisasi pemerintah daerah dan ditetapkanlah menjadi inspektorat. Inspektorat kabupaten luwu sudah mengalami pergantian pimpinan selama 5 kali sejak berdirinya hingga sekarang.

Tugas pokok dan fungsi inspektorat kabupaten luwu pada perda nomor 3 tahun 2009 tanggal 7 agustus 2009 adalah melakukan pengawasan umum terhadap pelaksanaan urusan pemerintahan umum, penyelenggaraan pemerintah daerah, pembinaan social politik, pelaksanaan pembangunan dan pembinaan kemasyarakatan di lingkungan pemerintah kabupaten luwu, pemerintah kecamatana, serta pemerintah desa dan kelurahan, dengan menjalankan fungsi sebagai berikut :

1. Inspektorat merupakan unsure pendukung tugas kepala daerah, sesuai dengan bidang kewenangan lembaga tehnis daerah sebagaimana ditetapkan dalam 
lampiran peraturan daerah kabupaten luwu nomor 03 tahun 2008 tentang urusan pemerintah yang menjadi kewenangan pemerintah kabupaten luwu.

2. Melaksanakan pemeriksanaan terhadap penyelenggaraan urusan pemerintah daerah, pemerintah desa/ kelurahan yang meliputi bidang pemerintahan, bidang social dan politik, perekonomian, kesejahteraan social, pembinaan aparatur, pendapatan daerah, kekayaan Negara dan daerah serta lain-lain yang di tugaskan.

3. Melakukan pengujian serta pemeriksaan atas hasil laporan setiap unsure dan atau instansi di lingkungan pemerintah kabupaten luwu.

4. Melakukan pengecekan kebenaran laporan keuangan atau pengaduan terhadap penyimpanan atau penyalahgunaan di bidang pemerintahan, pembinaan social politik, perekonomian, kesejahteraan social, pembinaan aparatur, pendapatan daerah serta kekayaan Negara/ daerah.

5. Melakukan pelayanan temuan administrasi dan fungsional

Pernyataan visi dan misi

Visi merupakan pandangan jauh kedepan, kemana dan bagaimana inspektorat kabupaten luwu harus dibawa serta berkarya agar konsisten dan dapat eksis, inovatif serta produktif . visi tidak lain adalah gambaran yang menantang tentang keadaan masa depan berisikan cita dan citra yang ingin diwujudkan oleh inspektorat kabupaten luwu dapat dijabarkan sebagai berikut : " mewujudkan pengawasan preventif dan refresif yang professional dengan mengutamakan prinsip-prinsip pembinaan dalam menunjang pelaksanaan pemerintahan”.

Penjelasan makna : memperhatikan peningkatan kompleksitas penyelenggaraan pemerintahan dan pembangunan memerlukan pengawasan yang semakin ketat, agar dapat berdaya guna dalam melaksanakan pemerintahan dan pembangunan dan pembinaan kemasyarakatan.

Untuk mewujudkan visi tersebut, inspektorat kabupaten luwu menetapkan misi sebagai berikut :

1. Menciptakan aparat pengawasan yang bersih dan professional dibidang tugasnya masing-masing.

2. Mengupayakan semua pelaksanaan kegiatan pemerintahan daerah berpedoman ketentuan perundang-undangan yang berlaku.

3. Menjalin hubungan koordinasi yang efektif dengan sesama aparat pengawasan program/ kegiatan di seluruh satuan kerja perangkat daerah (SKPD)

Analisis data penelitian

Analisis Deskriptif 
Tabel 2

Hasil Analisis Deskriftif

\begin{tabular}{|l|l|l|l|l|}
\hline variabel & $\begin{array}{l}\text { Kisaran } \\
\text { teoritis }\end{array}$ & $\begin{array}{l}\text { Kisaran } \\
\text { sesungguhnya }\end{array}$ & $\begin{array}{l}\text { Rata-Rata } \\
(\text { means })\end{array}$ & $\begin{array}{l}\text { Deviasi } \\
\text { standar }\end{array}$ \\
\hline $\begin{array}{l}\text { Factor } \\
\text { internal }\end{array}$ & $9-36$ & $25-36$ & 30,8000 & 2,78260 \\
\hline $\begin{array}{l}\text { Factor } \\
\text { eksternal }\end{array}$ & $9-36$ & $26-36$ & 31,333 & 2,79455 \\
\hline $\begin{array}{l}\text { Peranan } \\
\text { Internal } \\
\text { auditor }\end{array}$ & $9-36$ & $26-36$ & 31,333 & 3,17730 \\
\hline
\end{tabular}

Berdasarkan deskriptif data penelitian pada table 4.5 dapat diketahui bahwa :

1. Factor internal dengan indicator penilaian integritas, kompetensi dan objektivitas skor jawaban dengan kisaran 25 samapi dengan 36 dan kisaran teoritis 9 sampai dengan 36 dengan rata-rata 3,4 ( 30,80 dibagi dengan 9 ). Kisaran tersebut menunjukkan bahwa jawaban responden mengenai factor internl yang tinggi. Standar deviasi sebesar 2,78260 menunjukkan terdapat perbedaan jawaban responden yang satu dengan responden lainnya.

2. Factor eksternal dengan indicator penilaian pemberian imbalan, hubungan kekerabatan perubahan undang-undang/ peraturan pemerintah mempunyai skor jawaban dengan kisaran 26 sampai dengan 36 dan kisaran teoritis 9 sampai dengan 36 dengan rata-rata 3,5 ( 31,33 dibagi dengan 9 ). Kisaran tersebut menunjukkan bahwabjawaban responden mengenai factor eksternal yang tinggi. Standar deviasi sebesar 2,79455 menunjukkan terdapat perbedaan jawaban responden yang satu dengan responden lainnya.

3. Internal auditor dengan indicator pengawasan, pemeriksaan dan pembinaan mempunyai skor jawaban dengan kisaran 26 sampai dengan 36 dan kisaran teoritis 9 sampai dengan 36 dengan rata-rata 3,5 ( 31,33 dibagi dengan 9) kisaran tersebut menunjukkan bahwa jawaban responden mengenai peranan internal auditor yang tinggi. Standar deviasi sebesar 3, 17730 menunjukkan terdapat perbedaan jawaban responden yang satu dengan responden yang lain.

Analisis pengaruh factor internal dan factor eksternal terhadap peranan internal auditor inspektorat

Pengujian hipotesis

Untuk menguji hipotesis bahwa keahlian, indepedensi dan etika berpengaruh terhadap kualitas auditor dengan menggunakan uji $\mathrm{F}$ dan uji t.

Pengujian hipotesis dengan uji $\mathrm{F}$

Pengaruh variable independen dianalisis dengan menggunakan uji $\mathrm{F}$, yaitu dengan memperhatikan signifikansi nilai $\mathrm{F}$ pada output perhitungan dengan tingkat alph 5\%. Jika nilai signifikan uji $\mathrm{F}$ lebih kecil dari 5\% maka terdapat 
pengaruh antara semua variable indevenden terhadap variable dependen. Hasil pengujian uji F pada penelitian ini sebagai berikut:

Tabel 3

Hasil uji F

\begin{tabular}{|l|l|l|l|l|l|}
\hline Model & $\begin{array}{l}\text { Sum Of } \\
\text { Squares }\end{array}$ & df & $\begin{array}{l}\text { Mean } \\
\text { Square }\end{array}$ & F & sig \\
\hline 1 & 76.223 & 2 & 38.112 & 7.024 & $\mathrm{O}^{\mathrm{a}}$ \\
$\begin{array}{c}\text { Regresion } \\
\text { Residual } \\
\text { Total }\end{array}$ & 65.110 & 12 & 5.426 & & \\
\hline
\end{tabular}

Pada hasil uji regresi dalam penelitian ini diketahui nilai uji $\mathrm{F}$ sebesar 7,024 dengan signifikan F lebih kecil dari 5\%. Dengan demikian dapat disimpulkan bahwa semua variable independen dalam penelitian ini secara bersama-sama ( simultan ) berpengaruh terhadap peranan internal auditor inspektorat ( y). hal tersebut berarti jika factor internal (X1), factor eksternal (X2) secara bersama-sama mengalami kenaikan maka akan berdampak pada peranan internal auditor inspektorat (Y), sebaliknya jika factor internal ( X1), Faktor eksternal (X2 ) Secara bersama-sama mengalami penurunan maka akan berdampak pada penurunan peranan internal auditor inspektorat ( $\mathrm{y}$ ).

Pengujian hipotesis dengan uji $\mathrm{t}$

Dalam pengujian hipotesis dengan memperhatikan nilai t hitung dari hasil regresi tersebut untuk megetahui pengaruh variable independen secara parsial terhadap variable independen dengan dengan tingkat kepercayaan 95\% atau pada alpha 5\%. Dengan ayarat apabila nilai variable indevenden signifikan terhadap variable dependen, sedangkan apabila tidak signifikan maka tidak terdapat pengaruh antara variable dependen terhadap variable dapenden. Pada penelitian ini uji t digunakan untuk menguji apakah hipotesis yang diajukan dalam penelitian ini diterima atau tidak dengan mengetahui apakah variable independen secara individual mempengaruhi variable dapenden.

Adapun metode dalam penentuan $\mathrm{t}$ table menggunakan ketentuan tingkat signifikan 5\% dengan $\mathrm{df}=\mathrm{n}-\mathrm{k}$ ( dalam penelitian ini $\mathrm{df}=15-2=13$ ), sehingga didapat nilai $\mathrm{t}$ table sebesar 2, 160 disajikan dalam table sebagai berikut : 
Tabel 4

Hasil uji t

\begin{tabular}{|l|l|l|l|l|l|}
\hline variabel & $\begin{array}{l}\text { Standardised } \\
\text { coeffients } \\
\text { (bata })\end{array}$ & t Hitung & $\begin{array}{l}\mathrm{t} \\
\text { Tabel }\end{array}$ & Sig & Keputusan \\
\hline $\begin{array}{l}\text { Factor } \\
\text { internal } \\
\text { X1 })\end{array}$ & 0,152 & 0,772 & 2,160 & 0,455 & $\begin{array}{l}\text { Hipotesis } \\
\text { tidak } \\
\text { Terbukti }\end{array}$ \\
\hline $\begin{array}{l}\text { Factor } \\
\text { eksternal } \\
(\mathrm{X} 2)\end{array}$ & $\mathrm{O}, 699$ & 3,538 & 2,160 & 0,004 & $\begin{array}{l}\text { Hipotesis } \\
\text { Terbukti }\end{array}$ \\
\hline
\end{tabular}

Dari table 4.7 di atas diketahui nilai $t$ hitunmasing-masing dari variable independen. Dari nilai tersebut yang kemudian debandingkan dengan nilai $t$ table. Adapun penjabarnya adalah sebagai berikut : (a) Dari hasil perhitungan diperoleh angka $t$ hitung sebesar $0,772<t$ table sebesar 2,160 sehingga $\mathrm{H}_{\mathrm{O}}$ di terima dan $\mathrm{H}_{1}$ di tolak. Akhirnya tidak ada hubungan linier antarafaktor, (b) Dari hasil perhitungan di peroleh angka $t$ hitung sebesar 3,538_> $t$ table sebesar 2, 160 sehingga $H_{0}$ di tolak dan $\mathrm{H}_{1}$ di terima. Artinya ada hubungan linier antara factor eksternal yakni pemberian imbalan, hubungan kekerabatan dan perubahan undang-undang/ peraturan pemerintah. Besarnya pengaruh terhadap peranan internal auditor inspektorat, yaitu 0,699 atau $70 \%$ di anggap signifikan

Pembahasan hasil penelitian

Pada pengujian hipotesis berdasarkan hasil perhitungan dapat dikatakan bahwa factor internal dengan indicator penilaian integritas, kompetensi dan objektivitas, dan factor eksternal dengan indicator penilaian pemberian imbalan.

Fenomenanya yang terjadi di insfektorat kabupaten luwu bahwa tidak semua auditor internal yang ada inspektorat tersebut telah bersitifikasi auditor dan merupakan lulusan serjana jurusan akuntansi atau ekonomi.

Seorang auditor yang memiliki independensi yang tinggi tidak akan mudah terpengaruh dan tidak mudah di kendalikan oleh pihak lain dalam mempertimbangkan fakta yang dijumpai saat pemeriksaan dan merumuskan serta menyatakan pendapatnya. Dengan semakin independensinya seorang auditor maka akan mempengaruhi tingkat pencapaian pelaksanaan suatu pekerjaan yang semakin baik atau dengan kata lain kinerja akan menjadi lebih baik.

Hasil penilaian ini mendukung penilaian trisnanigsih ( 2007 ) yang membuktikan bahwa independensi auditor sebesar $3.111>1.960$ dan nilai probability atau nilai p lebih kecil dari $0.05(0.002<0.05)$ berpengruh terhadap kinerja auditor. Hasil penilaian ini sejalan dengan penilaian yang dilakukan wibowo ( 2009 ) bahwa terdapat pengaruh positif independensi auditor terhadap kinerja. 


\section{Penutup}

Kesimpulan penelitian ini adalah: (a) Factor internal tidak berpengaruh terhadap peranan inspektorat sebagai internal auditor di kabupaten luwu, (b) Factor eksternal berpengaruh terhadap peranan inspektorat sebagai internal auditor di kabupaten luwu, (c) Secara simutlan factor internal dan factor eksternal berpengaruh signifikan terhadap peranan inspektorat sebagai internal auditor di kabupate luwu. Adapun saran dari penelitian ini adalah: (a) Berdasarkan penilaian diatas factor internal tidak berpengaruh terhadap peranan inspektorat sebagai internal auditor,oleh karena itu, para internal auditor inspektorat harus memperhatikan integritasnya, (b) Berdasarkan penelitian diatas factor eksternal berpengaruh terhadap peranan inspektorat sebagai internal auditor, oleh karena itu, para internal auditor inspektorat harus tetap memperhatikan factor tersebut sehingga dalam menjalankan peranannya dapat lebih maksimal, (c) Disarankan untuk peneliti berikutnya, agar melanjutkan penelitian ini dengan berfokus pada variable yang belum diteliti pada penelitian.

\section{Daftas Pustaka}

Agoes, Sukrisno. 2004 auditing (pemeriksaan akuntan) oleh kantor Akuntan Publik. Edisi Ketiga. Penerbit: Fakultas Ekonomi Universitas Trisakti.

Algifari. 2000. Analisis Regresi. Yogyakarta: BPFE.

Arens, Loebbecke. 2003 Audit Pendekatan Terpadu. Salemba Empat: Jakarta.

Boynton dkk. 2003. Modern Auditing. Jakarta: Penerbit Erlangga. 2002. Modern Auditing. Edisi 7. Jakarta: Penerbit Erlangga.

Guy Dan M, Alderman C. Wayne, dan Winter Alan J, 2002, Auditing Jilid 1, dialih bahasakan oleh Paul A. Rajoe, dan Ichsan Setyo Budi, Edisi 5, Erlangga : Jakarta.

Halim, Abdul. 2003. Auditing ( Dasar-Dasar Audit Laporan Keuangan). Edisi 3. Yogyakarta.

Henry Simamora. 2002. Akuntansi Manajemen. Jakarta: UPPP AMP YKPN.

2005, Akuntansi Basis Pengambilan Keputusan Bisnis, Jakarta: Salemba Empat. 
Hiro, Tugiman. 2006. Standar Profesional Audit Internal. Yogyakarta: Kanisius.

Lawrence B. Sawyers. B. 2005, Audit Internal . alih bahasa Desi Adhariani. Salemba Empat: Jakarta.

Mardiasmo. 2009. Akuntansi Sektor Publik. Edisi 4. Penerbit Andi. Yogyakarta.

Mulyadi. 2002 Auditing. Buku Dua. Edisi ke 6. Salemba Empat. Jakarta.

Nasution, S. 2003. Metode Research. Jakarta: Bumi Aksara.

Riduwan. 2006. Dasar-Dasar Statistika. Edisi 5. Bandung: Alfabeta. 